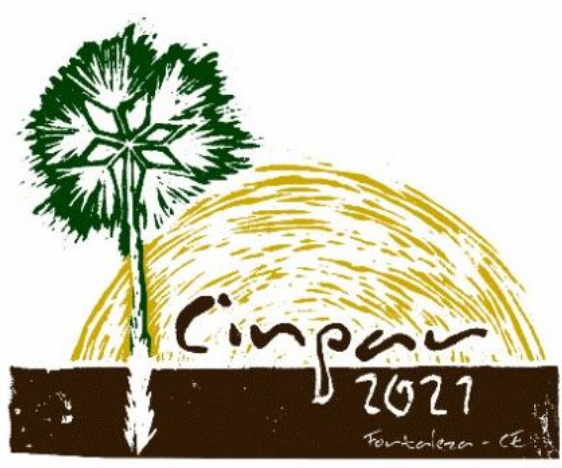

XVII Congresso Internacional sobre Patologia e Reabilitação das Construções

XVII Congreso Internacional sobre Patología y Rehabilitación de las Construcciones

XVII International Conference on Pathology and Constructions Rehabilitation

FORTALEZA (Brasil), 3 a 5 de junho de 2021

https://doi.org/10.4322/CINPAR.2021.106

\title{
Importância do controle na produção do concreto em obras de pequeno porte
}

\section{Importance of concrete production control in small buildings}

\author{
Marcelo Silva FERREIRA ${ }^{1}$, Fernando Nunes CAVALHEIRO ${ }^{2}$, Gustavo SAVARIS ${ }^{3}$, Carlos Eduardo Tino \\ BALESTRA $^{4}$, Lucia BRESSIANI ${ }^{5}$, Flavia de Fatima Emi MURAKAMI ${ }^{6}$ \\ ${ }^{1}$ Universidade Tecnológica Federal do Paraná, Campus Toledo, Brasil, massafer15@hotmail.com \\ 2 Universidade Estadual do Oeste do Paraná, Campus Toledo, Brasil, fernandonunescavalheiro@hotmail.com \\ ${ }^{3}$ Universidade Tecnológica Federal do Paraná, Campus Toledo, Brasil, gsavaris@utfpr.edu.br \\ ${ }^{4}$ Universidade Tecnológica Federal do Paraná, Campus Toledo, Brasil, carlosbalestra@utfpr.edu.br \\ ${ }^{5}$ Universidade Tecnológica Federal do Paraná, Campus Toledo, Brasil, bressiani@utfpr.edu.br \\ ${ }^{6}$ Universidade Tecnológica Federal do Paraná, Campus Curitiba, Brasil, flaviaemi21@yahoo.com.br
}

\begin{abstract}
Resumo: Em obras residenciais de pequeno porte, a produção de concreto geralmente é realizada no próprio canteiro, sendo o concreto empregado em elementos de volume reduzido, como fundações e pilares. Nestes casos não é comum o controle tecnológico do concreto, o que pode ocasionar o aparecimento de patologias, quando os resultados obtidos na prática não atendem aos considerados no dimensionamento. $\mathrm{O}$ objetivo deste trabalho foi analisar as resistências à compressão dos concretos produzidos em obras residenciais na cidade de Toledo-PR. Durante a produção dos concretos foi quantificada a proporção de materiais utilizada e amostras destes materiais foram coletadas para realização de ensaios, determinação das propriedades físicas e determinação do traço empregado. Ensaios de abatimento do tronco de cone foram realizados com o concreto no estado fresco e corpos de prova cilíndricos foram moldados para determinação da resistência à compressão em laboratório aos 28 dias. Verificou-se que somente 33,3\% das amostras atenderam aos padrões mínimos de resistência característica à compressão recomendada pela norma NBR 6118:14, o que evidencia uma das causas de patologias em edificações de pequeno porte.
\end{abstract}

Palavras-chave: Concreto. Resistência à compressão. Construção residencial. Patologias.

\begin{abstract}
In small residential construction, the production of concrete is usually performed on the construction site, and concrete is used in elements of reduced volume, such as foundations and columns. In these cases, concrete production control is not common, which can result in pathologies, when the strength obtained in practice do not reach those considered in the design. The objective of this work was to analyze the compressive strength of concrete produced to residential buildings at Toledo-PR. During the production of the concretes, the proportion of materials used was quantified and samples of these materials were collected to carry out laboratorial tests, determining the physical properties and proportion of material in mixture. Slump tests were performed with the concrete in a fresh state and cylindrical specimens were molded to determine the compressive strength in the laboratory at 28 days. It was found that only $33.3 \%$ of the samples reached the minimum characteristic compressive strength recommended by the standard NBR 6118: 14 , that may cause pathologies in small buildings.
\end{abstract}

Keywords: Concrete. Compressive strength. Residential building. Pathologies. 


\section{Introdução}

A engenharia civil é composta de áreas diversas, porém todos os conhecimentos convergem para um ponto comum que seria a construção de um sistema que possa garantir a solução de um determinado "problema" seja ele de moradia, transposição de caminhos, melhoria de condição publica, etc. Segundo Bauer (2000) é essencial ter o conhecimento prévio de todos os materiais que serão aplicados a sua atividade, com o intuito de entender e controlar os resultados esperados pelos mesmos.

A busca pelo controle de qualidade na engenharia civil se deve pelo fato das edificações não apresentarem a durabilidade esperada. E principalmente ao alto índice de reformas precoces necessárias para que a edificação mantenha o seu princípio fundamental construtivo, reformas essas que demandam recursos financeiros e podem ser evitadas se a obra for planejada e construída seguindo determinados padrões de qualidade.

Helene e Terzian (1992) determinam a palavra controle, como um conjunto de procedimentos técnicos, a partir dos quais é possível obter a qualidade esperada para uma boa funcionalidade do concreto. Qualidade pode ser definida como o processo de adequar-se a algo com o intuito de satisfazer o usuário.

A utilização dos métodos de dosagem dos concretos visa à aplicação de um controle de qualidade do processamento do concreto produzido em obra, estes procedimentos de dosagem são utilizados principalmente por grandes empresas de fornecimento de concreto. Uma boa dosagem deve apresentar uma resistência característica real do concreto, condizente com aquela calculada. Isso pode ser obtido em traços feitos em laboratórios, pois eles são feitos com total controle dos componentes.

Mas quando o concreto é preparado in loco, existem variáveis como: a umidade, água inapropriada, excesso de partículas de solo, que podem interferir na resistência final do concreto. Segundo Barboza e Bastos (2008) os traços empregados em obra normalmente utilizam de conceitos e tabelas antigas, que se tornaram ultrapassadas devido às atualizações das normas. Portanto são necessários novos estudos, que possam garantir que os padrões atuais sejam contemplados no dimensionamento da dosagem do concreto.

De acordo com Barboza e Bastos (2008), o concreto feito em obra, ainda torna-se necessário e viável, em alguns casos. Pois em obras de pequeno porte o volume de concreto utilizado nos elementos estruturais, como os pilares, não é maior que o volume mínimo vendido pelas indústrias de concreto inviabilizando assim a compra do concreto usinado.

Andrade e Tutikian (2011) mencionam diversas características e propriedades do concreto endurecido, mas de forma geral é dada ênfase à resistência mecânica e fatores que a influenciam, como a relação água/cimento, a idade do concreto, o tipo de agregado utilizado e o tipo de cimento. A análise da resistência à compressão, das amostras de concreto feito in loco, é importante para certificar que as construções locais, mesmo de pequeno porte, estejam atendendo as resistências mínimas estipuladas pela norma NBR 6118 (ABNT, 2014).

Vilela et al. (2018) avaliaram os métodos de controle tecnológico em concreto em obras civis de pequeno e médio porte na cidade de Ouro Branco (MG) e constaram que em obras com concreto moldado in loco, na maioria dos casos não são realizados quaisquer procedimentos para o controle de qualidade do concreto empregado, a trabalhabilidade no estado fresco não é mensurada e as resistências à compressão resultam em valores bem abaixo ao mínimo especificado pela NBR 6118 (ABNT, 2014).

O estudo desenvolvido por Ribeiro et al. (2016) indicou a evidente necessidade de reflexão sobre a qualidade do concreto produzido em obra, ressaltando que não há preocupação, ou ainda, falta conhecimento por parte dos profissionais em relação aos cuidados e procedimentos necessários para produção de concretos com qualidade satisfatória. Avaliando a resistência à compressão dos concretos produzidos em obra constatataram que, pelo menos, $50 \%$ das obras apresentavam resistências à compressão inferiores a $20 \mathrm{MPa}$.

A preocupação com a resistência dos concretos elaborados in loco se deve pelo grande volume de obras, em sua maior parte residencial, que utilizam deste tipo de procedimento para a confecção dos elementos estruturais, tais como: vigas, pilares e fundações, e assim, o presente trabalho se justifica ao avaliar as reais interferências no processo de produção do concreto em obras de pequeno porte, que refletem na resistência à compressão do concreto, objetivando uma melhora nas condições do controle de qualidade das obras. 


\section{Caracterização das obras e materiais}

Para a realização da pesquisa foram selecionadas doze obras, enquadradas no padrão de obras de pequeno porte definidas em IBRACON (2003) e localizadas na cidade de Toledo, Paraná, escolhidas aleatoriamente. Destas obras seis foram descartadas pois constatou-se que os materiais não eram mensurados antes da colocação na betoneira, e buscou-se obras com materiais de características semelhantes, como o tipo cimento adotado (CPII-Z-32) e agregados. Para garantir a privacidade dos proprietários e dos responsáveis técnicos as obras não serão identificados.

Os materiais granulares, areia e pedra britada, foram coletados em sacos plásticos para caracterização quanto à propriedades físicas: teor de umidade, massa específica e granulometria dos agregados graúdos e miúdos. Antes da preparação dos concretos, os recipientes utilizados para abastecimento das betoneiras foram medidos, com o intuito de se obter o volume de cada material usado, determinando assim o traço utilizado, com exceção do cimento, que era utilizado um saco de $50 \mathrm{~kg}$ por betonada.

Também foram coletadas as informações gerais da obra, como: existência de projeto estrutural e resistência à compressão axial do concreto almejada, tipo de peça a ser confeccionado, o tipo de construção e método de dosagem do concreto.

Logo após a produção dos concretos, foram realizados ensaios de consistência pelo abatimento do tronco de cone (slump test), conforme a NBR NM 67 (ABNT, 1998), e moldados seis corpos de prova cilíndricos (10 cm de diâmetro e $20 \mathrm{~cm}$ de altura), seguindo os procedimentos da NBR 5738 (ABNT, 2015). Após 24 horas os corpos de prova foram desmoldados e transportados para o laboratório de materiais de construção da Universidade Tecnológica Federal do Paraná - Campus Toledo, onde foram submseros em água para cura úmida, como indicada na NBR 9479 (ABNT, 2006).

Aos 28 dias de idade os corpos de prova capeados e submetidos ao ensaio de compressão axial, conforme está preconizado na NBR 5739 (ABNT, 2007), utilizando uma prensa hidráulica EMIC modelo PC200C.

\section{Resultados}

\subsection{Caracterização das obras}

Todas as obras analisadas possuíam um local fechado para o armazenamento do cimento, porém os agregados estavam depositados ao ar livre e em contato com o solo. A areia utilizada em todas as obras era proveniente de dragagem do rio Paraná e a pedra britada era de origem basáltica, e a água utilizada na produção do concreto era proveniente da compania de saneamento do Paraná (SANEPAR). No Quadro 1 são apresentadas as características de cada uma das obras selecionadas para o estudo e sua indicação na Figura 1 , onde são apresentadas imagens das obras.

Quadro 1 - Características das obras avaliadas

\begin{tabular}{|c|c|c|c|c|}
\hline Obra & $\begin{array}{c}\text { Tipo de } \\
\text { edificação }\end{array}$ & $\begin{array}{c}\text { Elemento } \\
\text { estrutural } \\
\text { concretado }\end{array}$ & $\begin{array}{c}\text { Havia projeto } \\
\text { estrutural? }\end{array}$ & $\begin{array}{c}\text { Indicação na } \\
\text { Figura 1 }\end{array}$ \\
\hline 1 & Residencial térrea & Pilares & Não & B \\
\hline 2 & $\begin{array}{c}\text { Residencial 2 } \\
\text { pavimentos }\end{array}$ & Vigas e lajes & Sim & C \\
\hline 3 & $\begin{array}{c}\text { Residencial 2 } \\
\text { pavimentos }\end{array}$ & Vigas baldrames & Sim & D \\
\hline 5 & $\begin{array}{c}\text { Residencial 2 } \\
\text { pavimentos }\end{array}$ & $\begin{array}{c}\text { Blocos de } \\
\text { fundação }\end{array}$ & Sim & E \\
\hline 6 & Residencial 2 & Pilares & Não & F \\
\hline
\end{tabular}



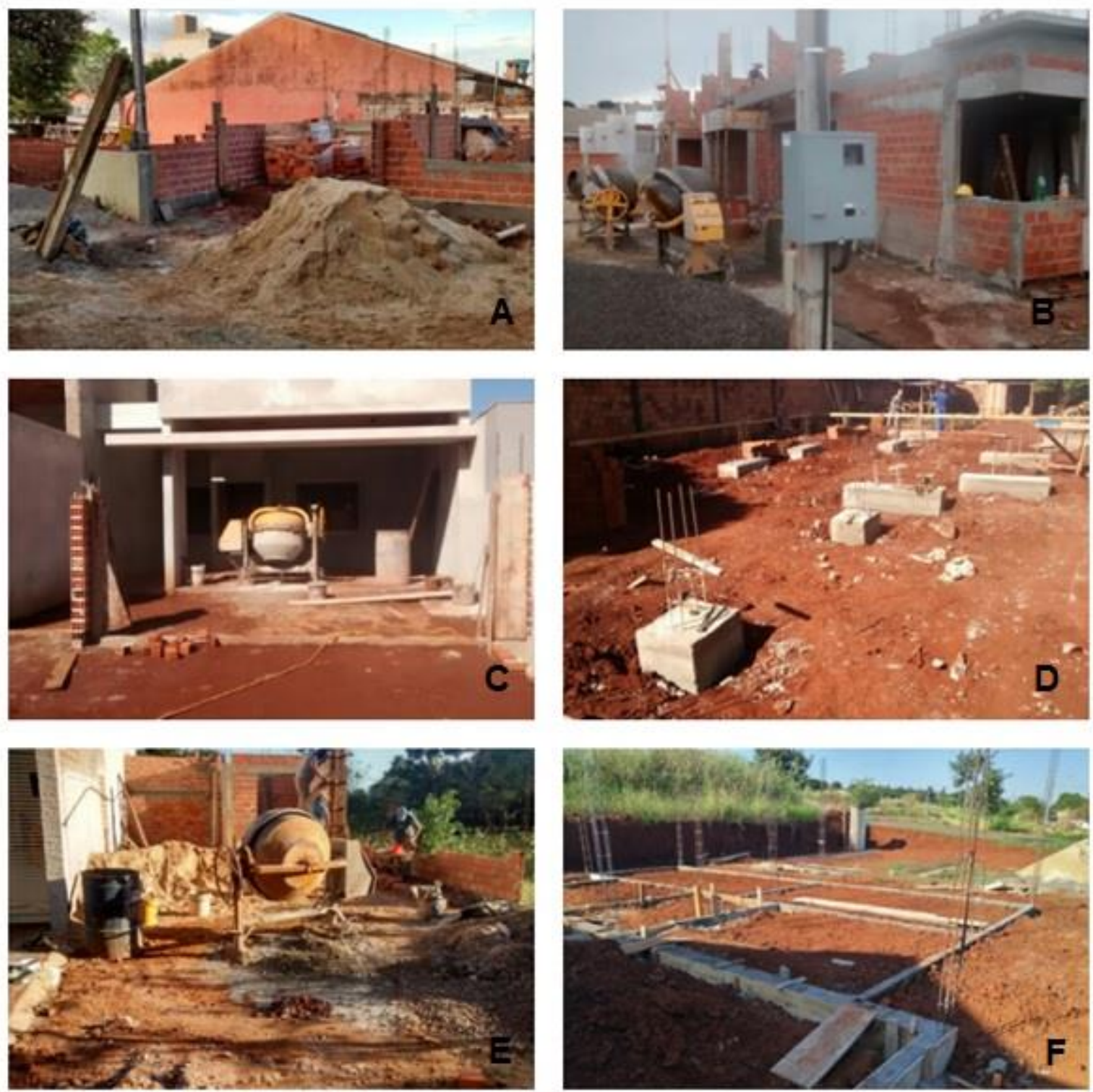

Figura 1 - Imagens das obras avaliadas

Na obra 2 o projeto estrutural não estava na obra na data da visita e nas obras 3 e 4 os projetos estruturais não indicavam o $f_{c k}$ adotado para o dimensionamento. Portanto para as comparações de resistência foi considerado um $\mathrm{f}_{\mathrm{ck}}$ mínimo de $20 \mathrm{MPa}$, como recomenda a norma NBR 6118 (ABNT, 2014).

\subsection{Propriedades dos materiais e traços dos concretos}

$\mathrm{Na}$ Tabela 1 são apresentados os resultados dos ensaios de teor de umidade e massa específica dos agregados miúdos e graúdos. 
Tabela 1 - Teor de umidade e massa específica dos agregados

\begin{tabular}{|c|c|c|c|c|}
\hline \multirow{2}{*}{ Obra } & \multicolumn{2}{|c|}{ Agregado miúdo } & \multicolumn{2}{c|}{ Agregado graúdo } \\
\cline { 2 - 5 } & $\begin{array}{c}\text { Teor de umidade } \\
(\%)\end{array}$ & $\begin{array}{c}\text { Massa específica } \\
\left(\mathbf{g} / \mathbf{c m}^{\mathbf{3}}\right)\end{array}$ & $\begin{array}{c}\text { Teor de umidade } \\
(\%)\end{array}$ & $\begin{array}{c}\text { Massa específica } \\
\left(\mathbf{g} / \mathbf{c m}^{\mathbf{3}}\right)\end{array}$ \\
\hline 1 & 2,36 & 2,65 & 1,21 & 2,91 \\
\hline 2 & 4,54 & 2,64 & 1,93 & 2,88 \\
\hline 3 & 3,39 & 2,65 & 1,54 & 2,87 \\
\hline 4 & 3,44 & 2,66 & 0,93 & 2,95 \\
\hline 5 & 3,01 & 2,65 & 2,82 & 2,81 \\
\hline 6 & 3,16 & 2,65 & 0,94 & 2,89 \\
\hline
\end{tabular}

As umidades calculadas foram utilizadas para correção da quantidade de água dos traços. As massas específicas dos agregados apresentam pequena variação entre as obras, devido ao material ser extraído na região oeste do Paraná.

Nas Figuras 2 e 3 são apresentadas as curvas granulométricas dos agregados miúdos e graúdos, respectivamente, obtidas pela média dos valores da porcentagem de massa passante nas peneiras de duas amostras avaliadas para cada obra. A granulometria dos agregados miúdos de todas as obras eram semelhantes, entretanto os agregados graúdos das obras 1 e 3 possuíam menor granulometria em comparação com as demais obras analisadas.

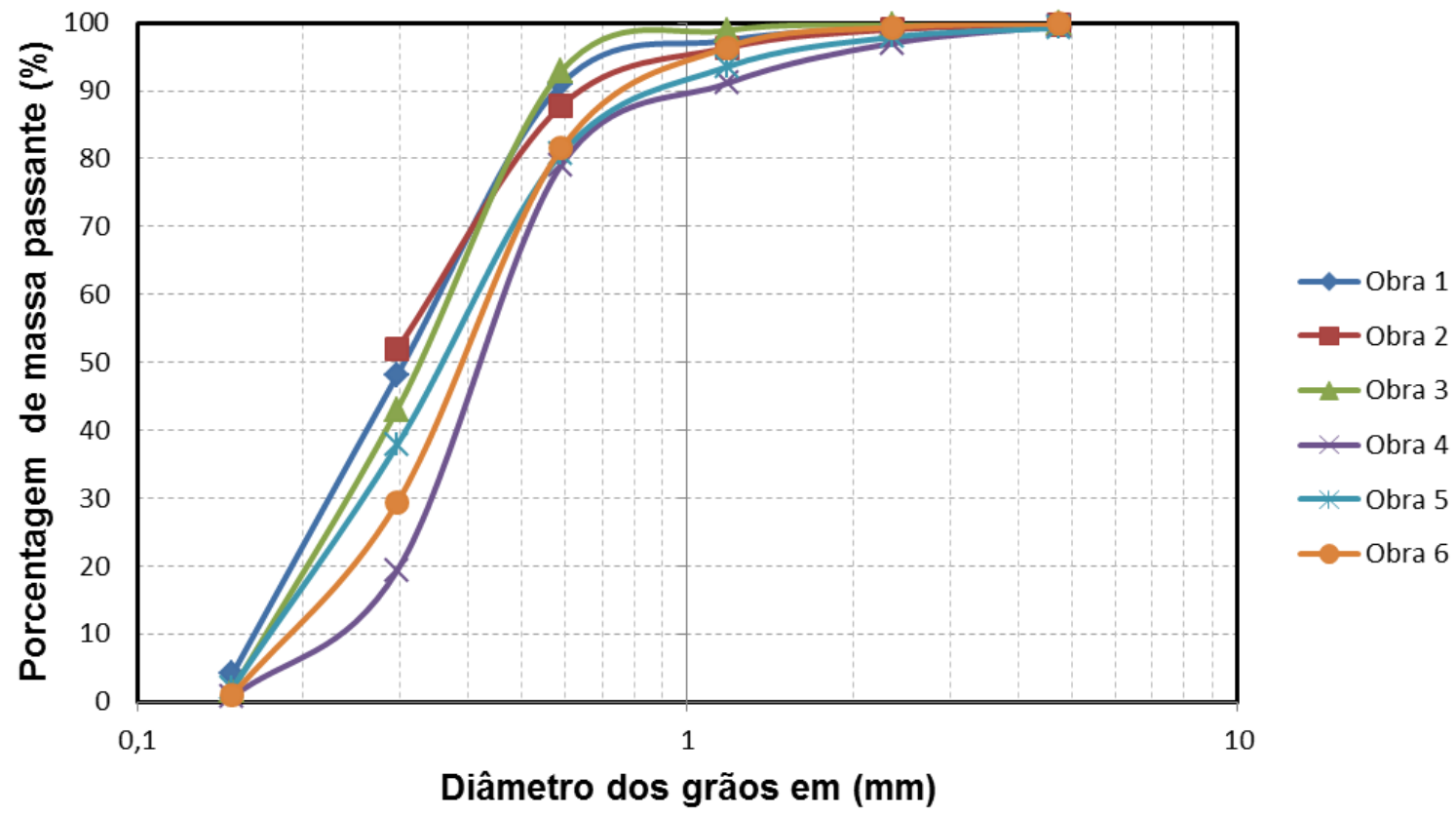

Figura 2 - Curvas granulométricas do agregado miúdo 


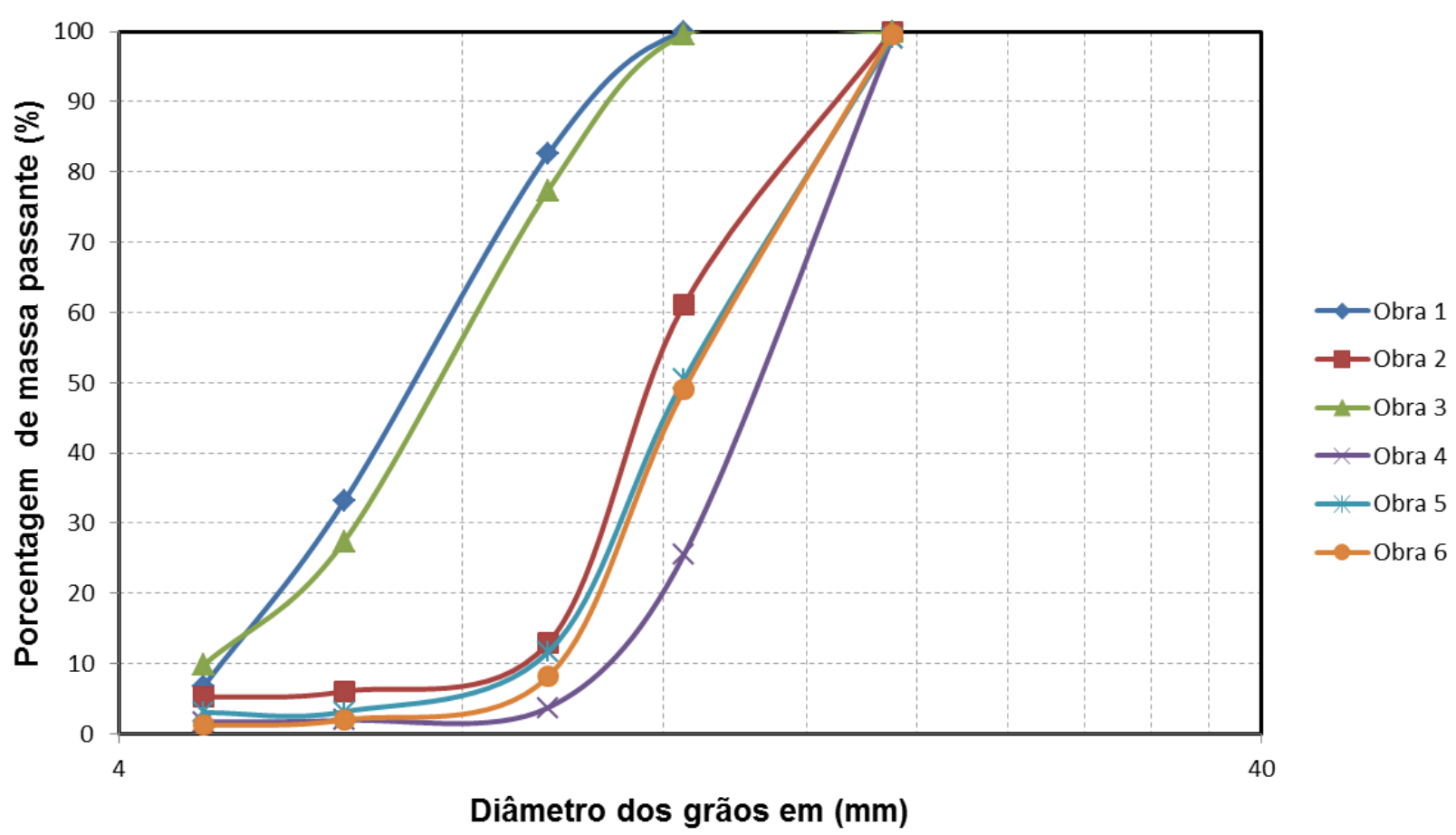

Figura 3 - Curvas granulométricas do agregado graúdo

A Tabela 2 apresenta os consumos de materiais medidos em obra para a produção de uma betonada de cada traço, não considerando a umidade dos agregados na quantidade total de água. Na Tabela 3 são apresentados os traços, em volume, e a relação água/cimento, descontando a umidade dos agregados e acrescendo este valor na quantidade de água.

Tabela 2 - Quantidades de materiais utilizadas para produção de uma betonada de concreto

\begin{tabular}{|c|c|c|c|c|}
\hline Obra & Cimento (kg) & Areia (L) & Brita (L) & Água (L) \\
\hline 1 & 50 & 82,53 & 73,36 & 64,72 \\
\hline 2 & 50 & 139,96 & 139,96 & 45,00 \\
\hline 3 & 50 & 139,96 & 139,96 & 23,05 \\
\hline 4 & 50 & 123,00 & 163,28 & 32,74 \\
\hline 5 & 50 & 212,06 & 148,44 & 62,20 \\
\hline 6 & 50 & 158,34 & 135,72 & 50,19 \\
\hline
\end{tabular}

Tabela 3 - Traços corrigidos, em volume, e relação água/cimento

\begin{tabular}{|c|c|c|c|c|c|}
\hline Obra & Cimento & Areia & Brita & Água/Cimento & $\begin{array}{c}\text { Teor de } \\
\text { argamassa (\%) }\end{array}$ \\
\hline 1 & 1 & 4,84 & 4,35 & 1,35 & 57,3 \\
\hline 2 & 1 & 8,02 & 8,24 & 1,08 & 52,3 \\
\hline 3 & 1 & 8,11 & 8,27 & 0,59 & 52,4 \\
\hline 4 & 1 & 7,13 & 9,71 & 0,77 & 45,6 \\
\hline 5 & 1 & 12,34 & 8,66 & 1,46 & 60,6 \\
\hline 6 & 1 & 9,2 & 8,07 & 1,13 & 55,8 \\
\hline
\end{tabular}


Analisando as proporções de materiais podem ser definidas três padrões distintos entre os traços utilizados. $\mathrm{O}$ traço da obra 1 apresenta pequeno volume de agregados e consequentemente maior consumo de cimento em relação aos demais, oposto ao traço da obra 5 que apresenta elevada quantidade de agregado miúdo e maior teor de argamassa. Exceto para o concreto da obra 3, a relação água/cimento apresentou valores elevados, acima do recomendado pela NBR 6118 (ABNT, 2014), que para classe de agressividade I limita em 0,65 , compromentendo assim a durabilidade da estrutura.

\subsection{Propriedades dos concretos nos estados fresco e endurecido}

Na Tabela 4 são apresentadas a trabalhabilidade medida com o concreto no estado fresco e os resultados dos ensaios de compressão axial realizados aos 28 dias.

Tabela 4 - Trabalhabilidade e resistência à compressão dos concretos

\begin{tabular}{|c|c|c|c|c|c|c|c|c|c|}
\hline \multirow{2}{*}{ Obra } & \multirow{2}{*}{$\begin{array}{c}\text { Abatimento } \\
\text { (cm) }\end{array}$} & \multicolumn{6}{|c|}{ Resistência à compressão (MPa) } & \multirow{2}{*}{$\begin{array}{l}\text { Média } \\
\text { (MPa) }\end{array}$} & \multirow{2}{*}{$\begin{array}{l}\text { Desvio } \\
\text { padrão } \\
\text { (MPa) }\end{array}$} \\
\hline & & 1 & 2 & 3 & 4 & 5 & 6 & & \\
\hline 1 & 18 & 5,53 & 5,73 & 5,40 & 5,25 & 5,25 & 5,65 & 5,47 & 0,20 \\
\hline 2 & 21 & 11,73 & 13,51 & 11,57 & 14,52 & 12,46 & 12,55 & 12,72 & 1,12 \\
\hline 3 & 10 & 33,38 & 33,66 & 32,16 & 35,07 & 31,46 & 33,83 & 33,26 & 1,25 \\
\hline 4 & 17 & 25,37 & 23,76 & 27,60 & 25,50 & 23,84 & 25,17 & 25,21 & 1,10 \\
\hline 5 & 18 & 11,64 & 10,85 & 10,77 & 11,50 & 10,42 & 11,18 & 11,06 & 0,47 \\
\hline 6 & 17 & 13,15 & 14,13 & 12,69 & 14,29 & 12,97 & 13,66 & 13,48 & 0,65 \\
\hline
\end{tabular}

A produção do concreto nas obras de pequeno porte é geralmente realizada pelos próprios operários, com base em seu conhecimento prático, visando garantir a trabalhabilidade do concreto. Como se observou, na maioria das obras a trabalhabilidade do concreto é elevada (acima de $16 \mathrm{~cm}$ ) o que facilita a etapa de lançamento do concreto. Para obter a elevada trabalhabilidade constatou-se o aumento da quatidade de água na mistura, com fatores a/c acima muitas vezes acima de 1 , o que resultou em redução da resistência à compressão axial, como pode ser observado na Figura 4.

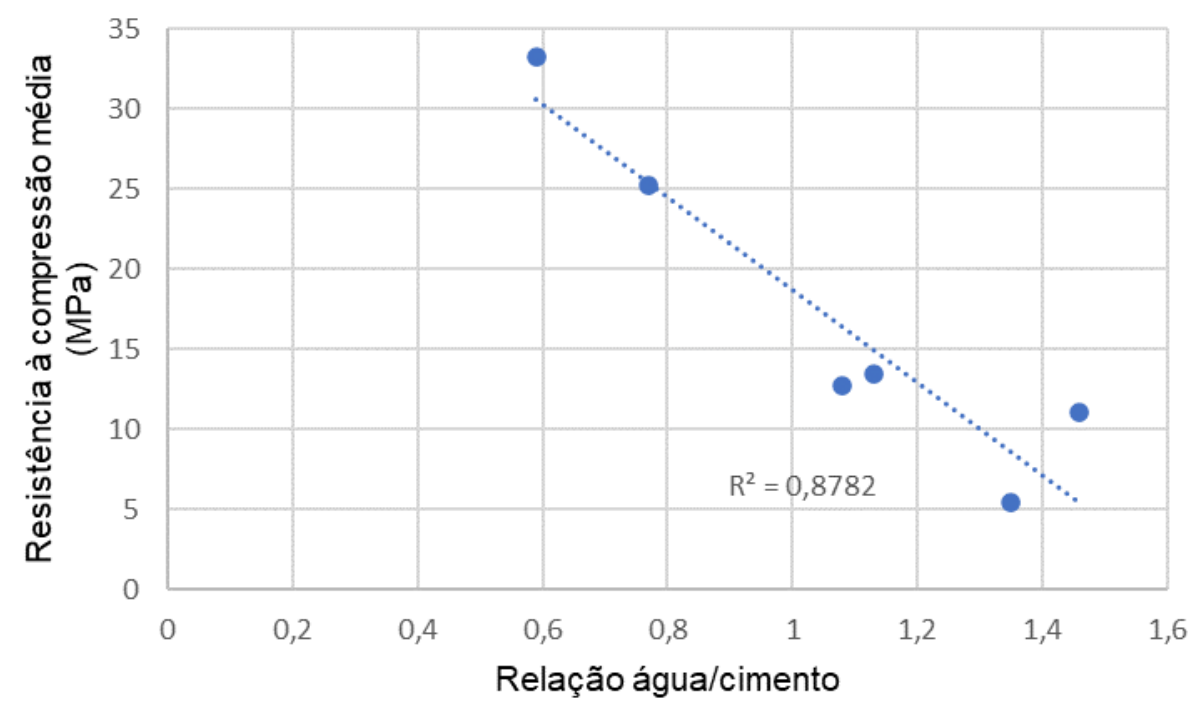

Figura 4 - Resistência à compressão média vs. relação água/cimento 
Dentre os concretos avaliados, somente aqueles das obras 3 e 4 apresentaram resistência à compressão média acima de $25 \mathrm{MPa}$, o que, considerando o desvio padrão, deve resultar em resistência à compressão característica acima de $20 \mathrm{MPa}$, recomendado pela NBR 6118 (ABNT, 2014).

A falta do controle tecnológico reflete não somente em riscos à segurança das estruturas, bem como a durabilidade das edificações, visto que elevada relação a/c resulta em concretos mais porosos, o que favorece a carbonatação.

\section{Conclusões}

O acompanhamento da produção de concreto em obras de pequeno porte e a determinação da resistência à compressão axial destes concretos permite estabelecer as seguintes conclusões:

Em obras de pequeno porte a dosagem dos materiais é realizada de forma expedita, sem controle da umidade dos agregados, sendo a trabalhabilidade adotada como um parâmetro qualitativo do concreto;

A elevada adição de água na mistura acarretou na redução da resistência à compressão dos concretos, para valores abaixo do recomendado por norma, comprometendo não somente a segurança da edificação, mas também sua durabilidade, visto que os critérios de dosagem também estão relacionados à vida útil.

\section{Agradecimentos}

Os autores agradecem à Universidade Tecnológica Federal do Paraná e ao Grupo de Pesquisas em Materiais e Estruturas (GPMAES) pelo suporte para realização deste trabalho.

\section{Referências Bibliográficas}

Andrade, J. J. de O., Tutikian, B. F. (2011). Resistência mecânica do concreto. In: Geraldo Cechella Isaia. (Org). Concreto: ciência e tecnologia. 1. ed. São Paulo: IBRACON. v.1. p. 615-652.

Associação Brasileira de Normas Técnicas (2015). NBR 5738: Concreto - Procedimento para moldagem e cura de corpos de prova. Rio de Janeiro.

Associação Brasileira de Normas Técnicas (2007). NBR 5739: Concreto - Ensaios de compressão de corposde-prova cilíndricos. Rio de Janeiro.

Associação Brasileira de Normas Técnicas (2006). NBR 9479: Argamassa e concreto - Câmaras úmidas e tanques para cura de corpos-de-prova. Rio de Janeiro.

Associação Brasileira de Normas Técnicas (1998). NBR NM 67: Concreto - Determinação da consistência pelo abatimento do tronco de cone. Rio de Janeiro, 1998.

Barboza, M. R., Bastos, P. S. dos S. (2008). Traços de concreto para obras de pequeno porte. Concreto e construção, v. XXXVI, p. 32-36.

Bauer, L. A. F. (2000). Materiais de construção: novos materiais para construção civil. 5. ed. Rio de Janeiro: LTC.

Helene, P., Terzian, P. (1992). Manual de dosagem e controle do concreto. 1. ed. Brasilia: SENAI.

Instituto Brasileiro do Concreto (2003). Estruturas de pequeno porte. Prática recomendada IBRACON para estruturas de edifícios de nível 1.

Ribeiro, R. R. J., Diógenes, H. J. F., Nóbrega, M. V., El Debs, A. L. H. C. (2016). Um estudo das propriedades mecânicas do concreto para fins estruturais preparado em canteiros de obras. Revista IBRACON de Estruturas e Materiais, 9(5), 722-744.

Vilela, D. T. N., Coimbra, K. F., Borba Jr., J. C., Duarte, L. N., Mazon, A. A., Reis, M. F. M.. Estudo do controle tecnológico do concreto em obras civis na cidade de Ouro Branco (MG). In. Anais do $60^{\circ}$ Congresso Brasileiro do Concreto. Foz do Iguaçu, 2018. 